\title{
Reflexiones jurídicas en torno a la participación de la sociedad civil en los Comités de Desarrollo Regional de Estados y Municipios Mineros en México
}

\author{
García Moraga Reyna Elizabeth, Bracamonte Ozuna Mario Alfonso², \\ Torres García Elizabeth ${ }^{3}$ \\ ${ }^{1}$ García Moraga Reyna Elizabeth, profesora investigadora de la Universidad de Sonora Campus Caborca. \\ ${ }^{2}$ Bracamonte Ozuna Mario Alfonso, profesor de horas sueltas de la Universidad de Sonora Campus Caborca. \\ 3 Torres, Elizabeth, Investigadora, Ave. Universidad e Irigoyen s/n colonia Ortiz, Caborca Sonora.
}

\section{Resumen}

A partir de los noventa diversas naciones de América Latina se dieron a la tarea de actualizar y adaptar sus legislaciones mineras en dos grandes vertientes: garantizar jurídicamente un desarrollo sustentable y vigilar con mayor énfasis las inversiones en el ramo para regular los diversos impactos que generan las empresas que se encuentran asentadas en determinadas localidades. México es uno de ellos. La aplicación de instrumentos legales permite a la autoridad gubernamental construir una plataforma fiscal en impactos ambientales y de desarrollo regional.

El Congreso de la Unión aprobó en 2014 diversas disposiciones de derechos sobre minería, destacando adiciones a los artículos 271 y 275 de la Ley Federal de Derechos con la finalidad de apoyar a comunidades mineras. Se implementó el Fondo para el Desarrollo Regional Sustentable de estados y municipios mineros cuyo objetivo es elevar la calidad de vida de habitantes de las zonas de extracción minera.

A través de esta investigación se realizan reflexiones jurídico-sociales en torno al ejercicio y distribución del Fondo Minero como retribución de recursos a las comunidades mineras del país mediante obras de impacto social y se analiza la integración y facultades del Comité de Desarrollo Regional para las zonas implicadas bajo un esquema de participación ciudadana efectiva.

Palabras clave: Fondo Minero, Participación Ciudadana.

\section{Legal reflections on the participation of civil society in the Regional Develop- ment Committees of Mining States and Municipalities in Mexico}

\begin{abstract}
Since the nineteen-hundreds, several countries in Latin America have taken on the task of updating and adapting their mining legislations in two major areas: the first one is to legally guarantee their sustainable development and, secondly, to monitor investments with greater emphasis as well as regulating the impacts generated by the companies that are located in certain areas. Mexico is one of them. The implementation of legal instruments allows the Government to build a fiscal on environmental impacts and regional developments.
\end{abstract}

In 2014 the Congress of the Union approved various provisions on mining rights, highlighting additions to articles 271 and 275 of the Federal Law of Rights in order to support the mining communities. This is how the Fund for the Sustainable Regional Development of Mining States and Municipalities was implemented, which objective is to raise the quality of life of the inhabitants of the mining extraction zones.

This research will carry out a series of legal and social reflections on exercise and distribution of the Mining Fund as a reward for the mining communities in the country through social impact works as well as the analysis of integration and authority of the Regional Development Committee for the involved areas under a scheme of effective citizen participation.

Keywords: Mining Fund, Citizen Participation.

*Autor para envío de correspondencia: Departamento de Ciencias Sociales, Ave. Universidad e Irigoyen s/n colonia Ortiz, Caborca Sonora, C.P. 83621 Tel. 63737

222 82. E-mail reynael@caborca.uson.mx.

(c) 2019 Editorial UNISON — URN. Derechos reservados. 


\section{INTRODUCCIÓN}

La industria minera es uno de los sectores más dinámicos de la economía mexicana, de ahí que nuestro país se encuentra posicionado dentro de los principales productores de minerales metálicos incluso desde la época prehispánica. Actualmente tiene presencia en 24 de las 32 entidades del país y en 200 municipios. Esta industria, junto con la agricultura, es la que tiene mayor relación con comunidades y municipios, aunque el desarrollo no ha estado exento de conflictos en algunas de las comunidades donde realizan sus operaciones sobre todo en materia ambiental.

A partir de la década de los noventa, diversas naciones de América Latina han revisando, actualizando y adaptando sus legislaciones mineras sobre la base de vigilar con mayor énfasis las inversiones en el ramo y para regular los diversos impactos que generan las empresas que se encuentan asentadas en determinadas localidades. México ha sido uno de ellos. La aplicación de instrumentos legales permite a la autoridad gubernamental construir una plataforma fiscal con énfasis en impactos ambientales y de desarrollo regional que incida directamente en los espacios donde se encuentran asentadas las minas.

Pero esa legislación no es del todo halagüeña. Se continua subordinando el derecho de las personas a participar en las decisiones que les afectan para decidir sobre su propio desarrollo (Fundar, 2002). En efecto, una de las cuestiones que más reclaman las comunidades es el desconocimiento sobre los proyectos mineros y las consecuentes afectaciones positivas o no que les derivarán de tal forma que existe un enorme vacio de información sobre temas relevantes como son la salud pública, sustentabilidad y la biodiversidad, por ejemplo, a más de una notoria descoordinación en el tema de las dependencias gubernamentales involucradas directamente.

Lo anterior genera un irracional uso del agua, producción de toneladas de residuos peligrosos, daños irreparables a las comunidades por contaminación de agua, suelo y aire como resultado de esa descoordinación, de una falta de vigilancia e incluso una sórdida permisión de la autoridad en un país donde las dos terceras partes del territorio es región árida y semiárida. Se hace énfasis en la existencia de una real participación ciudadana con un significado social de vastos alcances en pro de una vida colectiva plena e integralemente desarrollada como requisito para alcanzar los objetivos del desarrollo local y ambiental sustentable.

Cabe aquí destacar la importancia Precisamente en el tema del agua Aburto en (Fundar, Centro de Análisis e Investigación, A.C., 2017) indica que para extraer un centenario de oro (1.2 onzas) se requieren de 100 a 150 mil litros de agua dulce, lo que se traduce en proporcionar agua a una familia por un año. Por su parte, el Consejo Consultivo del Agua, A.C. organización de la Sociedad Civil en México, indica que el $10 \%$ de la población carece de agua y el $43 \%$ no cuentan con instalaciones sanitarias mínimas. Cifras tan alarmantes requieren un análisis profundo del costo-beneficio social, de los retos presentes y futuros de la seguridad hídrica en la que la industria minera tiene un elevando impacto ya que agota el suministro de agua dulce.

Según el Anuario Estadístico de la Minería Mexicana (Servicio Geológico Mexicano, 2018) el valor de la producción minero-metalúrgica de minerales concesibles tuvo un valor en el año 2017 de 241.7 mil millones de pesos (Mmp) en tanto que el valor de la producción a precios corrientes de la minería mexicana ampliada, significó un monto total de 575 Mmp lo que implica un incremento de $20.9 \%$ con relación a 2016. Se denomina minería ampliada a aquella que incluye minerales metálicos, no metálicos y productos metalúrgicos exceptuando petróleo, gas y minerales radiactivos. (Servicio Geológico Mexicano, 2017),
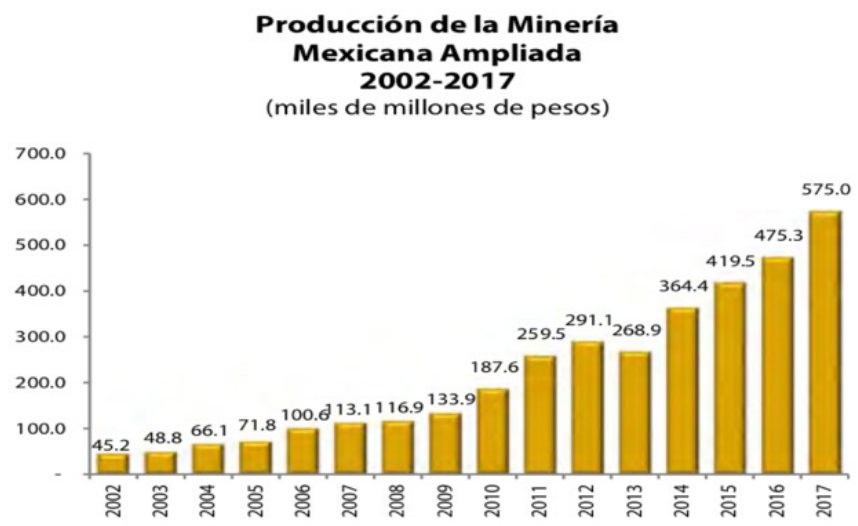

Fuente: Servicio Geológico Mexicano (SGM, 2017)

La producción minera en México se concentra en cuatro entidades federativas básicamente, esto es, Sonora, Zacatecas, Jalisco y Chihuahua, con una escala de participación menor por lo que toca a Guanajuato.

Según datos del Instituto Nacional de Estadística, Geografía e Informática (INEGI) la economía mexicana creció a 2.3\%, su menor ritmo desde hace cuatro años, en tanto que la industria minera mostró en 2017 un repunte aceptable debido a políticas de reducción de costos, eficiencia operativa, mejora de rendimiento entre otros. El punto de encuentro se ha dado entre lo fiscal y lo ambiental (Acquatella Jean, 2005) al generarse una tríada entre el financiamiento del gasto público, la inversión en infraestructura y la gestión ambiental bajo condiciones macro fiscales restrictivas (Delgado, 2010) generando así que la industria minera sea mejor aceptada en los espacios geográficos donde se localizan, mas no por eso se minimizan los impactos cuantitativos y cualitativos 
que agravan el descontento social y los escenarios de violencia y conflicto que se presentan. Los temas fiscales provocaron preocupación en el sector minero en lo relativo a regulación, certeza jurídica y de inseguridad en la materia. (Cámara Minera de México, 2018),

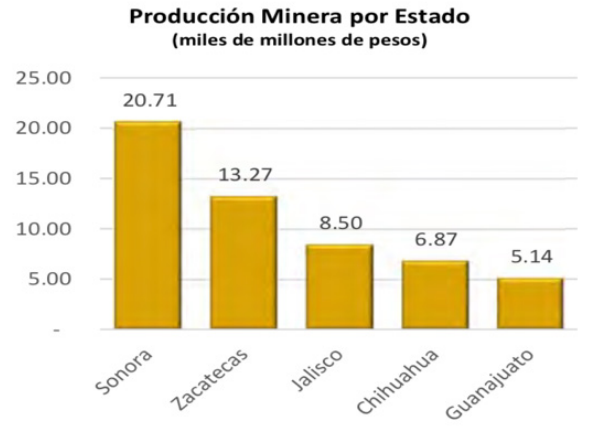

Fuente: Servicio Geológico Mexicano (SGM, 2017)

Ante este problema constante y en el marco de las discusiones en torno al presupuesto federal 2014, a propuesta del Ejecutivo Federal, el Congreso de la Unión aprobó diversas disposiciones en materia de derechos sobre minería, destacando adiciones a los artículos 271 y 275 de la Ley Federal de Derechos (a.Diputados, 2018) con la finalidad de apoyar a las comunidades mineras. Dicha ley crea el Fondo para el Desarrollo Regional Sustentable de estados y municipios mineros cuyo objetivo es elevar la calidad de vida de los habitantes de las zonas de extracción minera (Fondo Minero).

La novedad del tema, la importancia de los recursos que se asignan al indicado Fondo, así como los impactos sociales que se generan en las comunidades beneficiarias constituyen fuertes elementos a considerar para analizar el origen, distribución, aplicación, ejercicio y transparencia de las asignaciones para un auténtico desarrollo sustentable que incluya a la sociedad civil organizada en la toma de decisiones de aquel. En total se han distribuido de 2014 a 2017 la cantidad de $\$ 11,327,131,800.00$ millones de pesos.

El objetivo de la presente investigación es realizar una serie de reflexiones jurídico-sociales en torno al ejercicio y distribución del Fondo Minero en la retribución de recursos a las comunidades mineras del país a través de obras de impacto social así como analizar la integración y facultades del Comité de Desarrollo Regional para las zonas implicadas, cuya figura se establece en los Lineamientos para la aplicación de los recursos del Fondo Minero (b.DOF, 2017), órgano colegiado encargdo de definir la aplicación de los recursos y derivar al final en una serie de recomendaciones y propuestas que permitan la inclusión de la sociedad civil en dicho órgano de decisión.

\section{MATERIALES Y MÉTODOS}

La investigación que se presenta es de tipo cualitativa documental al panorama jurídico mexicano actual, basada en la selección y recopilación de información de la lectura y crítica de documentos y no pretende probar teorías o hipotesis sino que analiza a través de la legislación mexicana actual su proximidad a la realidad, mediante datos y comprensión del tema sobre el Fondo Minero como instrumento de apoyo a las comunidades y municipios afectados. Es además una investigación analítico-descriptiva ya que se refiere al análisis de leyes, reglamentos y lineamientos aplicables así como a situaciones y eventos concretos sobre algunas de las cuestiones que determinan el fenómeno; busca respuestas a una situación en específico y no se trata exclusivamente de obtener y acumular datos sino de relacionarlo con condiciones y conexiones existentes.

\section{RESULTADOS Y DISCUSIÓN}

El papel que la minería ha tenido en el curso de la historia mexicana es relevante; fue una de las causas principales para la colonización y establecimiento de asentamientos humanos incluso desde tiempos precolombinos. Una red de carreteras y v ías férreas tienen su origen y justificación debido al florecimiento de esta actividad; en torno a ella se han erigido sectores de servicio, turismo y comercial, entre otros. Lo paradójico es que la industria minera ha sufrido una importante transformación en su estrutura empresarial, lo que no ha sido igual -hasta hace poco- respecto a la legislación mexicana, sobre todo por ser una actividad de alto impacto y con fuertes repercusiones en lo social, político, ambiental y económico. La cuestión es si la mineria puede contribuir al desarrollo sustentable de las localidades y regiones mineras donde tienen asiento empresas mineras (Buitelaar, 2001).

Ahora bien, un desarrollo regional sustentable solo puede alcanzarse con el progreso equilibrado de cada uno de sus componentes: economía, sociedad y protección al ambiente, tres conceptos que deben caminar unidos en pos de una calidad de vida al corto, mediano y largo plazo (García Moraga, 2016). Una minería saludable requiere la participación de todos los actores involucrados directa o indirectamente en ella, en la que el desarrollo sustentable permee en todos los aspectos de la sociedad de una forma responsable, cierta, segura, en armonía con el medio ambiente y las comunidades donde se establecen. Un instrumento efectivo de control es el pago de impuestos sobre esta actividad puesto que además se generan recursos fiscales que financian proyectos impulsados por los 
gobiernos federal y municipal acorde a las características y necesidades regionales y locales.

Un caso interesante es Perú, que cuenta con un Fondo Minero administrado por una Comisión Técnica de Coordinación; los proyectos están dirigidos hacia aspectos de nutrición, educación, salud, desarrollo y fortalecimiento de capacidades de gestión pública, desarrollo en la promoción de cadenas productivas, infraestructura básica, y obras de impacto social (Arbaiza, 2011).

A partir de la Reforma Fiscal 2014 y concretamente con la reforma al artículo 275 de la Ley Federal de Derechos (a.Diputados, 2018) que en lo general regula el pago por el uso o aprovechamiento de los bienes del dominio público de la Nación, se establece que los estados y la ciudad de México participarán en los ingresos de los derechos sobre minería de acuerdo a las cuotas por hectárea de concesiones y asignaciones mineras. La distribución del Fondo Minero es en un $62.5 \%$ a los municipios y demarcaciones territoriales de la Ciudad de México y el $37.5 \%$ restante a la entidad federativa correspondiente.

Lo anterior se traduce un miles de millones de pesos que trascienden lo jurídico tocando incluso lo social, económico, político, y de participación ciudadana como elementos indispensables para un desarrollo sustentable real. En la voz de Pablo Wong-González en el sentido contemporáneo del desarrollo regional, el territorio se convierte también en un factor clave para la competitividad económica regional. (Wong-González, 2009).

El Fondo Minero se ha convertido hoy por hoy, en un motor destacado en el desarrollo de las comunidades que se benefician con estos recursos. La sola cantidad global destinada a ello lo justifica:

Montos anuales asignados al Fondo

Tabla 1. Elaboración propia con datos de https://www.gob. $\mathrm{mx} /$ sedatu/acciones-y-programas/fondo-minero-para-eldesarrollo-regional-sustentable

\begin{tabular}{|c|c|}
\hline Año & Monto total \\
\hline 2014 & $\$ 2,090,718.508 .98$ \\
\hline 2015 & $2,191,742,278.79$ \\
\hline 2016 & $3,339,293,494.93$ \\
\hline 2017 & $3,705,377,518.00$ \\
\hline Total & $\$ 11,327,131,800.00$ \\
\hline
\end{tabular}

El Fondo es un contrato de mandato público celebrado por la SEDATU, (Mandante) con alguna institución de banca de Desarrollo (Mandatario) que en el caso es el Banco de Ahorro Nacional y Servicios Financieros (BANSEFI) quien lleva a cabo la administración de los recursos y los entrega a cada entidad federativa, además de tiene derecho a percibir como honorarios anuales hasta el $2.5 \%$ de los intereses que genere la inversión de los recursos en la Cuenta Concentradora. A partir de la anterior reforma se emitieron las Reglas Generales de Operación de los Comités de Desarrollo Regional de las Zonas Mineras (a.DOF, 2018)

Los objetivos del Fondo Minero son favorecer el desarrollo integral de municipios y comunidades en inversión física con un impacto social, ambiental y de desarrollo urbano positivo como son la construcción, remodelación y equipamiento de centros escolares, centros públicos urbanos, obras de pavimentación y mantenimiento de calles y caminos locales, alumbrado público sustentable, servicios públicos sobre la base de la eficiencia energética y energías renovables. También en obra de infraestructura para la protección ambiental como rellenos sanitarios, plantas de tratamiento de agua, instalación y mantenimiento de obras de drenaje público, manejo integral de residuos sólidos urbanos, mejora y monitoreo de calidad del aire, agua y suelo y suministro de agua potable.

Se consideran las obras que preserven áreas naturales, obras que afecten de manera positiva la movilidad urbana, transporte público respetuoso con el ambiente y de bajas emisión de carbono. Es clara la diferencia que existe entre la aplicación de recursos que destina Perú, al que se tiene en México. El Fondo Minero tiene, como se definió antes, el objetivo de beneficiar a poblaciones donde se desarrollen actividades mineras, pero por otra parte deben considerarse mecanismos que garanticen la transparencia, el acceso a la información, participación ciudadana y la rendición de cuentas en la asignación de los recursos así como el establecimiento de indicadores que midan los resultados sobre la base de políticas públicas bien claras, pero esto no sucede, pese a que existen informes de la distribución de los recursos, la información no se encuentra publicada en un formato adecuado para ser analizada a más de existir vacíos importantes de la misma (Aroa, 2017).

\section{DISCUSIÓN DE LOS RESULTADOS}

Ley Federal de Derechos establece en el artículo 275 la creación de los Comités de Desarrollo Regional para las Zonas Mineras en tanto que las Reglas Generales de Operación de los Comités de Desarrollo Regional para las Zonas Mineras (Reglas), (SEDATU, 2018) precisan la operatividad de los mismos. En cuanto a la integración de estos (a.DOF, 2018) preside el órgano colegiado el titular de la SEDATU y en su ausencia será representado por el titular de la Unidad, de la Dirección General y la Dirección de Organización de dicha Secretaría según sea el caso. El representante de la entidad federativa será designado por el 
Gobernador siempre y cuando posea nivel de secretario y no menor de director general.

Los municipios en donde se localicen actividades de explotación y obtención de minerales serán representados por un presidente municipal elegido por el presidente del Comité, dentro de los tres municipios que tengan mayor participación económica en el Fondo Minero, el que podrá durar en el cargo hasta 3 años, siempre que continúe su investidura de presidente municipal, un representante de las comunidades indígenas o núcleos agrarios en los casos en que se realicen estas actividades y finalmente se prevé como integrante a las empresas mineras por conducto de un representante electo entre aquellas con actividades relevantes de explotación y obtención de sustancias minerales en el estado. Todos los integrantes poseen voz y voto en tanto que el presidente del Comité Regional ejerce voto de calidad en caso de empate.

El hecho de que sea el titular de la SEDATU quien designe al presidente municipal encuentra su fundamento en el Artículo 3 de las Reglas Generales de Operación de los Comités de Desarrollo Regional para las Zonas Mineras (a.DOF, 2018) y deberá ser de entre los tres municipios que tengan mayor participación en el Fondo. Entre una serie de funciones del Comité Regional se encuentra el aprobar proyectos de inversión física (PIF) bajo ciertas condiciones:

a) Que tengan una visión de impacto territorial a escala regional, considerando el carácter intermunicipal del propio Fondo Minero,

b) Eleven la calidad de vida de las personas de las generaciones presente $y$ las futuras $y$

c) Preserven el equilibrio ecológico, la protección del ambiente y el aprovechamiento de los recursos naturales.

Los estados y municipios que tengan participación en el Fondo Minero adquieren carácter de instancias ejecutoras respecto a los PIF que hayan propuesto y sean aprobados por el Comité, lo que significa que es atribución de los municipios presentar a la Dirección General del Fondo los PIF con la justificación de los impactos arriba indicados. Son los municipios los que tienen la facultad de priorizar los PIF y acceder a los recursos de aquel una vez cumplidos los requisitos, así como solicitar las ministraciones y cumplir lo estipulado en la normatividad inherente.

Como se observa, la importancia de la toma de decisiones respecto a los PIF queda constreñida a un grupo de personas las que, si bien cuentan con una determinada representación, requieren por fuerza y por necesidad de las comunidades la participación de la sociedad civil pero no se genera esta participación. Cabe hacer hincapié en que la reforma de 2014 se presenta en una época en que en el concierto mundial el papel de la sociedad civil es de lo más importante; el mundo se está preparando para implementar una nueva agenda de desarrollo y es menester dar voz a aquella. En esencia el Fondo Minero es el resarcimiento económico del daño causado por actividades mineras y ese resarcimiento solo se entiende a partir de una efectiva participación dentro del Comité Regional de la sociedad civil a través de una representación específica como miembro activo que vigile que el daño causado se traduzca no solamente en obras, sino en proyectos que empoderen a la sociedad civil.

Aún más, los proyectos de inversión física se generan a partir de fichas técnicas de identificación de proyectos de inversión física que presentan los municipios a través de sus presidentes municipales y no se establece injerencia alguna de participación ciudadana, la de la sociedad civil directamente receptora de los beneficios y no tiene, por ende, acceso a este mecanismo institucional que permitiría una interacción real entre las demandas ciudadanas y la toma de decisiones. Ante esta falta de participación se generan problemas de legitimidad desde la perspectiva social pues carecen de certidumbre respecto a los proyectos aprobados vía Fondo Minero el que finalmente es un acto de justicia social para generar prosperidad en comunidades mineras.

Hoy por hoy ha quedado rebasado con mucho el debate sobre si debe o no existir participación ciudadana en el ejercicio y control del gobierno, un tema ciertamente complejo en el México contemporáneo. Esta confusión se debe principalmente a la popularización de conceptos tales como participación, transparencia y rendición de cuentas. La primera constituye un eje importante de intervención ciudadana en asuntos de interés colectivo a través de la creación de espacios donde se debaten, deciden y vigilan tanto las políticas públicas como las de planeación, aplicación y ejecución de obras y acciones. Dicha participación solo se concibe con la intervención organizada de ciudadanos individuales o de organizaciones sociales y civiles en los asuntos públicos que se lleva a cabo en espacios y condiciones definidas (Isunza, 2006).

Pero esta participación debe traducirse en prácticas efectivas. Participación ciudadana entendida como aquella donde la sociedad tiene una injerencia directa, de mayor involucramiento en la administración pública tanto para la prestación de servicios como en la elaboración de políticas públicas (Serrano Rodríguez, 2015) e incluso en la toma de decisiones que repercuten en las mismas comunidades como sucede con el Fondo Minero que representan recursos económicos en cuya aplicación, ejecución y vigilancia deben ser cuestiones prioritarias. 
Ahora bien, en los propios municipios a que se alude, no existe ningún órgano colegiado con participación ciudadana que tenga facultades de intervención en la toma de decisiones del Fondo Minero, de tal forma que las decisiones son tomadas casi exclusivamente por el presidente municipal quien eleva los proyectos PIF para su aprobación al Comité Regional el que, bajo sus propias reglas, en su mayoría desconocidas, determina a cuántos y cuáles proyectos se habrán de destinar los recursos.

Boisier aborda al aprendizaje colectivo como forma de enfrentar la incertidumbre y la necesidad creciente de coordinación donde las regiones que aprenden son los territorios que mejor enfrentan el juego globalizador $y$ hacen de su capacidad de aprendizaje una condición especial para ganar y que se convierte en experta en cinco actividades principales: 1 ) es capaz de resolver problemas de una manera sistémica, 2) es capaz de experimentar nuevos enfoques, 3) es capaz de aprovechar su propia experiencia para aprender, 4) es capaz de aprender de las experiencias y prácticas más apropiadas de otras organizaciones y 5) es capaz de transmitir rápida y eficazmente el conocimiento a todo lo largo y ancho de su propia estructura. A este estadio deben evolucionar los municipios en su tránsito hacia las regiones inteligentes, ya que si no se es inteligente en la sociead del conocimiento, no existe posibilidad de salir de posiciones marginales y perdedoras. (Boisier, 2011).

\section{CONCLUSIONES Y RECOMENDACIONES}

Con la reforma a la Ley de Derechos en sus artículos 271 y 275, se constituyó el Fondo para el Desarrollo Regional sustentable de Estados y Municipios Mineros con la recaudación del pago de Derechos para la realización de obra de infraestructura social.

El Fondo Minero es una vía de obtención de recursos relativamente nueva, de enorme impacto en las comunidades y municipios donde existe extracción minera; representa el resarcimiento de los daños ambientales y comunales que se generan por esta actividad, cuyo objetivo es elevar la calidad de vida de los habitantes en las zonas de extracción minera. La cantidad de recursos que se han destinado a partir de la reforma de la Ley Federal de Derechos en 2014 revela la importancia de la exigencia normativa y de transparencia que debe existir sobre el particular tanto en la estructura orgánica, de participación ciudadana y funciones de cada integrante, debiéndose incluir la representación de la sociedad civil.

La opacidad, la falta de transparencia, la toma de decisiones unilaterales de un grupo de personas sin que medie una normativa específica no solo sobre la verificación, control y seguimiento de los proyectos de inversión física, sino que además se otorgue a la sociedad civil una representación específica dentro del Comité de Desarrollo Regional resulta imprescindible para la sanidad en el manejo y objetivos del Fondo Minero. Ni la Ley Federal de Derechos, ni la Reglas ni los Lineamientos aquí señalados con vastedad han considerado la participación ciudadana per sé dentro del órgano colegiado de mayor envergadura en el esquema del Fondo Minero, en claro menoscabo de la transparencia que debe prevalecer en todo acto de gobierno asociando el concepto de transparencia con el de publicidad, entendida como la cualidad de lo que es o puede hacerse público (López Ayllón, 2017) y en el caso no lo es.

El Fondo debe concebirse como un eje transversal que coadyuve al logro de los objetivos y metas planeados por las administraciones locales en el Plan de Desarrollo Municipal tal y como constitucionalmente está obligado; los ayuntamientos no deben convertirse en la práctica en un cómodo receptor del Fondo Minero sino que debe constituir una herramienta para alcanzar objetivos y metas establecidos en el indicado Plan de Desarrollo que contiene por disposición constitucional una visión a largo plazo La novel existencia del Fondo Minero requiere una exhaustiva revisión en lo que se refiere a normatividad principalmente en cuanto a la estructura de los órganos de decisión y facultades de éste, siendo imperativo además incorporar al ya existente Comité de Desarrollo Regional para las Zonas Mineras la participación de la sociedad civil con facultades de voz y voto dentro de ese órgano.

Se deben transparentar los procedimientos de asignación, ejercicio y aplicación de recursos a los municipios a través de la creación de Comités Municipales que vigilen la planeación, programación y evaluación de los recursos provenientes del Fondo para que sean las propias localidades las que en apego a su autonomía constitucional decidan y vigilen libremente sobre el destino final de aquellos.

La participación ciudadana debe generarse no como un derecho ni como una concesión gubernamental sino como una parte sine qua non en todo proceso de gestión para el desarrollo local en las diversas etapas de ejercicio del Fondo Minero. El propio Estado debe propiciar el establecimiento de reglas, criterios y acciones que fomenten la participación ciudadana, considerando además que la responsabilidad social no es una etiqueta ni un concepto empresarial de uso exclusivo sino de alcances comunitarios que incluye al Estado, las comunidades a través de la sociedad organizada y los gobiernos locales. $\mathbf{0}$

\section{BIBLIOGRAFÍA}

Acquatella, J. (2005). Política Fiscal y medio ambiente, Bases para una agenda común. Cepal. 
Arbaiza, L. (enero de 2011). Strategic Alliances: A negotiation and sustainable instrument from interculturality. Revista LAN, 70, 102-117.

Aroa, B. (2017). Las actividades extractivas en México: Estado actual. (C. d. Fundar, Ed.) México, México: Fundar, A.C. Recuperado el 16 de noviembre de 2018, de Fundar.org: http://fundar.org.mx/mexico/ pdf/3.4.Mecanismosparalatransferencia.pdf

Boisier, S. (2011). El territorio en la contemporaneidad. Revista Líder, 18, 9-24.

Buitelaar, R. (2001). Aglomeraciones Mineras y Desarrollo Local en América Latina. Alfa-Omega.

Cámara Minera de México. (2018). Informe de la Octagésima Primera Asamblea General Ordianria de la Cámara Minera de México. México, México.

Delgado, C. (2010). Ecología Política de la Minería en América Latina. México: UNAM.

Diputados, C. d. (16 de noviembre de 2018). Cámara de Diputados del H. Congreso de la Unión. Obtenido de www.diputados.gob.mx: http://www.diputados.gob.mx/ LeyesBiblio/pdf/107_221217.pdf

a.DOF. (16 de noviembre de 2018). Reglas Generales de Operación de los Comités de Desarrollo Regional para las Zonas Mineras. México.

b.DOF. (2017). DOF-Diario Oficial de la Federación. Recuperado el 17 de noviembre de 2018, de www.dof. gob.mx: https://www.gob.mx/cms/uploads/attachment/ file/242808/Acuerdo_Reforma_a_Lineamientos.pdf
Fundar, Centro de Análisis e Investigación, A.C. (2002). Investigaciones sobre el impacto de la inversión canadiense en México. México, México.

Fundar, Centro de Análisis e Investigación, A.C. (2017). Las actividades extractivas en México: Estado actual. Anuario 2016. México, México

García Moraga, R. E. (2016). La sustentabilidad como potenciador del desarrollo regional: el caso de municipios del rio Altar. En La Región Hoy (págs. 151173). México: IIEc.

López Ayllón, S. (2017). La transparencia gubernamental (Vol. 1). México, México, México: UNAM.

Isunza, E. (2006). Relaciones Sociedad Civil-Estado en México. Un ensayo de interpretación.

SEDATU. (16 de noviembre de 2018). Diario Oficial de la Federación. Obtenido de DOF - Diario Oficial de la Federación: https://www.gob.mx/cms/uploads/ attachment/file/242809/Reglas_de_Operacion.PDF

Serrano Rodríguez, A. (enero-abril de 2015). La participación ciudadana en México. Estudios Políticos (México)(34).

Servicio Geológico Mexicano. (2018). Anuario Estadístico de la Minería Mexicana, 2017. México, México .

Wong-González, P. (2009). Ordenamiento ecológico y ordenamiento territorial: retos para la gestión del desarrollo regional sustentable en el siglo XXI. Estudios Sociales, 10-39 